\title{
Chemosensitization of plant pathogenic fungi to agricultural fungicides
}

\author{
Vitaly Dzhavakhiya ${ }^{1}{ }^{*}$, Larisa Shcherbakova ${ }^{2}$, Yulia Semina $^{1}$, Natalia Zhemchuzhina ${ }^{1}$ and Bruce Campbell ${ }^{3}$ \\ 1 Laboratory of Molecular Biology, Russian Research Institute of Phytopathology, Moscow Region, Russia \\ ${ }^{2}$ Laboratory of Physiological Plant Pathology, Russian Research Institute of Phytopathology, Moscow region, Russia \\ ${ }^{3}$ Plant Mycotoxin Research Unit, Western Regional Research Center, United States Department of Agriculture - Agricultural Research Service, \\ Albany, CA, USA
}

\section{Edited by:}

Jong H. Kim, United States Department of Agriculture Agricultural Research Service, USA

Reviewed by:

Michael Wink, Heidelberg University, Germany

Ameeta Agarwal, University of Mississippi, USA

*Correspondence:

Vitaly Dzhavakhiya, Laboratory of Molecular Biology, Russian Research Institute of Phytopathology, VNIIF, B. Vyazyomy, Moscow Region 143050, Russia.

e-mail:dzhavakhiya@yahoo.com
A common consequence of using agricultural fungicides is the development of resistance by fungal pathogens, which undermines reliability of fungicidal effectiveness. A potentially new strategy to aid in overcoming or minimizing this problem is enhancement of pathogen sensitivity to fungicides, or "chemosensitization." Chemosensitization can be accomplished by combining a commercial fungicide with a certain non- or marginally fungicidal substance at levels where, alone, neither compound would be effective. Chemosensitization decreases the probability of the pathogen developing resistance, reduces the toxic impact on the environment by lowering effective dosage levels of toxic fungicides, and improves efficacy of antifungal agents. The present study shows that the antifungal activity of azole and strobilurin fungicides can be significantly enhanced through their co-application with certain natural or synthetic products against several economically important plant pathogenic fungi. Quadris (azoxystrobin) combined with thymol at a non-fungitoxic concentration produced much higher growth inhibition of Bipolaris sorokiniana, Phoma glomerata, Alternaria sp. and Stagonospora nodorum than the fungicide alone. The effect of Dividend (difenoconazole) applied with thymol significantly enhanced antifungal activity against $B$. sorokiniana and S. nodorum. Folicur (tebuconazole) combined with 4-hydroxybenzaldehyde (4-HBA), 2,3-dihydroxybenzaldehyde or thymol significantly inhibited growth of Alternaria alternata, at a much greater level than the fungicide alone. In addition, co-application of Folicur and 4-HBA resulted in a similar enhancement of antifungal activity against Fusarium culmorum. Lastly, we discovered that metabolites in the culture liquid of Fusarium sambucinum biocontrol isolate FS-94 also had chemosensitizing activity, increasing S. nodorum sensitivity to Folicur and Dividend.

Keywords: chemosensitization, plant pathogenic fungi, agricultural fungicides

\section{INTRODUCTION}

Co-application of some conventional industrial fungicides (triazoles and strobilurins) with certain phenolic acids or benzo analogs, which target cellular oxidative stress-response systems, enhanced antifungal activity of these fungicides against pathogenic yeasts and filamentous fungi causing invasive mycoses in humans or postharvest decay in agricultural products (Kim et al., 2008, 2010b; Faria et al., 2011; Kim and Campbell, 2011). Based on these findings and preliminary screening of substances showing promise as chemosensitizing agents, we selected several natural and synthetic compounds, viz. 2,3-dihydroxybenzaldehyde (2,3DHBA), 4-hydroxybenzaldehyde (4-HBA), thymol (2-isopropyl5-methylphenol), as putative chemosensitizers to test against plant pathogenic fungi exposed to fungicides extensively used in agriculture. Two of the aforementioned benzaldehydes are effective chemosensitizers for Candida, Aspergillus, and Penicillium strains and species (Faria et al., 2011). For instance, in vitro co-application of 2,3-DHBA and kresoxim-methyl or antimycin A resulted in complete inhibition of A. fumigatus and P. expansum growth, and $70 \%$ inhibition of $A$. flavus growth. Alternatively, application of these compounds individually resulted in only slight inhibition of fungal growth (Kim et al., 2008). In addition, 2,3-DHBA acted as a chemosensitizing agent to overcome fludioxonil resistance of $P$. expansum, commonly referred to as blue mold of apples, in vitro (Kim et al., 2010b). Thymol, a natural monoterpene derivative of cymene from Thymus vulgaris oil, is believed to disrupt fungal cell membrane integrity by reducing ergosterol content (Pinto et al., 2006). This natural product, alone, has been reported to completely block growth of toxigenic Aspergillus spp. and P. expansum at concentration of $5 \mathrm{mM}$ (Kim et al., 2006b). However, when thymol is combined with the antimycotic drugs, amphotericin B, fluconazole, or itraconazole, there is a synergistic increase in antifungal activity against C. albicans and Cryptococcus neoformans (Faria et al., 2011).

Along with plant derived thymol, we selected metabolites of a non-pathogenic and non-toxigenic fungus, Fusarium sambucinum isolate FS-94, for testing as putative chemosensitizers. These metabolites were tested because the culture liquid from FS94 on specially selected media was found to produce substances that at very low concentrations inhibited spore germination of the 
wheat glume/leaf blotch agent, Stagonospora nodorum (Semina et al., 2011).

This paper reports results of in vitro examination of 2,3-DHBA, 4-HBA, thymol, and FS-94 metabolites to significantly increase the sensitivity of certain plant pathogenic fungi, of economic importance to Russian agriculture, to several commercial fungicides. The fungicides include commercial azoles and strobilurins, which are routinely applied as fungicides on cereals, potato, and many other crops.

\section{MATERIALS AND METHODS FUNGI}

Phytopathogenic fungi tested included Alternaria alternata, Alternaria sp., Bipolaris sorokiniana, Fusarium culmorum, Phoma glomerata, and $S$. nodorum, from strains maintained in the Russian State Collection of Phytopathogenic Organisms.

\section{FUNGICIDES}

The commercial fungicides tested included Quadris, SC 25\% (a.i. Azoxystrobin), Dividend, SC 3\% (a.i. Difenoconazole), and Folicur, EC 25\% (a.i. Tebuconazole), which are commonly applied on cereals and grains. Concentrations of the active ingredients of the fungicide are indicated in the tables and figures.

\section{PUTATIVE CHEMOSENSITIZERS}

Thymol (2-isopropyl-5-methylphenol), 4-hydroxybenzaldehyde (4-HBA), and 2,3-dihydroxybenzaldehyde (2,3-DHBA), were purchased from Sigma Co. (St. Louis, MO, USA). Filtrates of culture liquids (FCL) of F. sambucinum isolate FS-94 were obtained by filtration after culturing on a liquid molasses-sucrose-ammonium medium according to Semina et al. (2011).

\section{ANTIFUNGAL BIOASSAY}

To study the influence of chemosensitizers on the plant pathogens and on their sensitivity to fungicides, the fungi were grown on agar media supplemented with different concentrations of the sensitizers or various doses of the fungicides.

Thymol, 4-HBA, 2,3-DHBA, or the fungicides were sterilized by filtration of their solutions through a Millipore $0.22 \mu \mathrm{m}$ membrane. The filtrates were added, individually, to PDA or Czapek agar medium, to final concentrations ranging from 10 to $90 \mathrm{ppm}$ (thymol), 10 to $1000 \mathrm{ppm}$ (4-HBA), 1 to $500 \mathrm{ppm}$ (2,3-DHBA), 0.1 to $100 \mathrm{ppm}$ (Quadris), 0.25 to $100 \mathrm{ppm}$ (Folicur), and 1 to 20 ppm (Dividend), prior to being poured into Petri dishes and before inoculation with test pathogenic fungi. Two microvolumes of FCL, 20 and $100 \mu \mathrm{l} / \mathrm{ml}$ of PDA, were used in the experiments with $S$. nodorum (strain \#13-1/3), making the final FCL concentrations 2 and 10 volume percent, respectively. Culture media, supplemented with putative chemosensitizers and/or the fungicides, were then inoculated by placing small fragments of fungal mycelia in the center of the dishes. Effects of treatments on growth were determined by culturing fungi in the dark at $25^{\circ} \mathrm{C}$ for 7 days, followed by measurement of colony diameter. We first determined the concentrations of sensitizers and fungicides that slightly suppressed growth of fungi, as compared to controls, and considered these as sub-fungicidal concentrations. These sub-fungicidal concentrations were selected for determining interactions between fungicides and test compounds in co-application experiments to define putative chemosensitization to the fungicides.

After determinating sub-fungicidal concentrations of test chemosensitizers and fungicides, Petri plate bioassays of combinations of chemosensitizers and fungicides were used against plant pathogens. The fungi were cultivated in the dark at $25^{\circ} \mathrm{C}$ from 7 to 23 days, depending on the tested pathogen. Control cultures, without addition of the test chemosensitizers, fungicides or their combinations, were grown under the same conditions. By the end of the culture period, fungal colony diameters were measured and colony size calculated as the area of a circle $\left(\mathrm{cm}^{2}\right)$. Growth inhibition was determined as percentage of diminished growth of treated fungi based on average diameter or area of colonies, as compared to controls. Enhanced antifungal activity was defined as where inhibition of fungal growth in co-application of putative chemosensitizers and a test fungicide significantly $(p<0.05)$ exceeded growth inhibition calculated as an arithmetical sum of either individual component.

\section{STATISTICAL TREATMENT}

Each experiment on fungal growth in the presence of putative sensitizers, commercial fungicides, or their combinations was performed in triplicate, per each concentration used, then replicated once. Quantitative data of the experiments were statistically analyzed with Microsoft software STATISTICA 6.0 (StatSoft Inc.). Means of different treatments, SE and SD, and significant differences $(p<0.05)$ of means among treatments and controls were determined using a $t$-test for independent variables. In the figures, bars on bracketing points on line graphs and histograms represent SEM or SD. Error bars on histogram columns representing arithmetical sums of effects of fungicides, alone, and chemosensitizing test agents, alone, are averages of SEM of the individual treatments.

\section{RESULTS}

The capability of thymol to increase fungicidal activity was investigated in combination with Quadris, toward P. glomerata, B. sorokiniana, Alternaria sp., and S. nodorum, and with Dividend, against $B$. sorokiniana and $S$. nodorum, and with Folicur, toward A. alternata.

Among these plant pathogens, the maximal synergistic effect resulted from co-applications of thymol and Quadris, at selected concentrations of $10 \mathrm{ppm}(0.07 \mathrm{mM})$ and $100 \mathrm{ppm}$, respectively, was observed toward B. sorokiniana. When thymol was applied separately at $10 \mathrm{ppm}$ there was practically no inhibition of pathogen growth (1.1\%). However, a thymol-Quadris combination produced almost three times higher growth inhibition (40.9\%) than the individual fungicide (14.8\%; Table 1). In the case of $P$. glomerata and Alternaria sp., the thymol-fungicide combinations were also significantly higher in antifungal activity than either thymol or Quadris applied individually. There was an almost doubling of growth inhibition from thymol-Quadris co-applications than Quadris alone, for both pathogens (Table 1). Co-application of thymol with Quadris resulted in $88.8 \%$ inhibition of $P$. glomerata growth. This inhibition was almost two times higher in comparison to this fungicide application alone. This inhibition exceeded by $27.5 \%$ the arithmetical sum of $61.3 \%$ 
of thymol (12.5\%) and Quadris (48.8\%), alone, respectively. The growth inhibition of Alternaria sp. produced by the thymolQuadris combination (36.4\%) was, again, significantly greater by $13 \%$, as compared to the arithmetical sum of growth inhibition $(23.8 \%)$ of individual fungicide (19.3\%) and thymol (4.5\%) applications.

Application of thymol and Quadris at $10 \mathrm{ppm}$, alone, resulted in either minor or no growth inhibition of $S$. nodorum and P. glomerata. Whereas, when these substances were co-applied at these same concentrations there was a significant enhancement of antifungal activity of Quadris (Figure 1).

Subsequent experiments showed thymol also sensitized $B$. sorokiniana and S. nodorum to Dividend, and A. alternata to
Folicur. Much greater inhibition of B. sorokiniana and S. nodorum colony growth was induced by Dividend in combinations with thymol as compared to treatments with the individual substances. Most notable is that addition of $1 \mathrm{ppm}$ of Dividend in nutrient media together with thymol $(10 \mathrm{ppm})$ produced as high a fungicidal effect on both these fungi as would require a 10-fold higher concentration (10 ppm) of Dividend alone (Figures 2 and 3 ). Moreover, a significant increase in antifungal activity was observed when a combination of Dividend and thymol, each applied at sub-fungicidal concentrations ( $1+10 \mathrm{ppm}$, respectively) was used against B. sorokiniana in two additional experiments (Figure 3). Co-application of these compounds resulted in $68 \%$ inhibition of fungal growth. This is in contrast to a predicted non-interactive

Table 1 | Fungicidal effect of thymol, Quadris, and their combination toward three plant pathogens at day 14 of in vitro testing.

\begin{tabular}{|c|c|c|c|c|c|c|c|}
\hline \multirow[t]{3}{*}{ Fungi } & \multirow{3}{*}{$\begin{array}{l}\text { Diameter of control } \\
\text { colonies, } \mathrm{mm}\end{array}$} & \multicolumn{6}{|c|}{ Substances and concentrations, ppm } \\
\hline & & \multicolumn{2}{|c|}{ Thymol, 10} & \multicolumn{2}{|c|}{ Quadris, 100} & \multicolumn{2}{|c|}{ Thymol, 10 + Quadris, 100} \\
\hline & & $\begin{array}{l}\text { Colony } \\
\text { diameter, mm }\end{array}$ & $\begin{array}{l}\text { Growth } \\
\text { inhibition, \% }\end{array}$ & $\begin{array}{l}\text { Colony } \\
\text { diameter, mm }\end{array}$ & $\begin{array}{l}\text { Growth } \\
\text { inhibition, \% }\end{array}$ & $\begin{array}{l}\text { Colony } \\
\text { diameter, } \mathrm{mm}\end{array}$ & $\begin{array}{l}\text { Growth } \\
\text { inhibition, \% }\end{array}$ \\
\hline B. sorokiniana & 88 & 87 & $1.1^{*}$ & 75 & 14.8 & 52 & 40.9 \\
\hline P. glomerata & 80 & 70 & 12.5 & 41 & 48.8 & 9 & 88.8 \\
\hline Alternaria sp. & 88 & 84 & 4.5 & 71 & 19.3 & 52 & 36.4 \\
\hline
\end{tabular}

${ }^{*}$ Percent growth inhibition not significantly different from control.

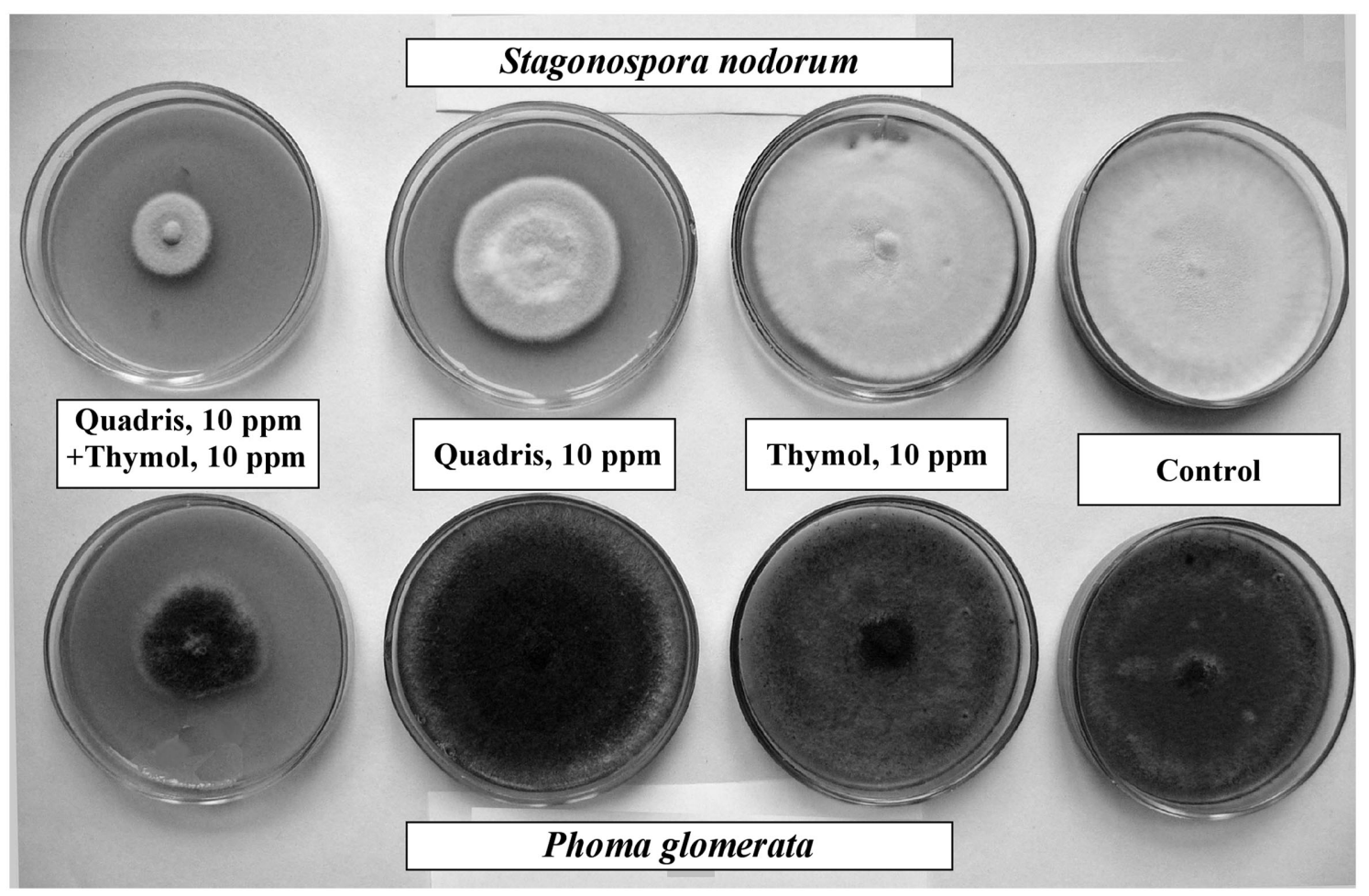

FIGURE 1 | Photographs of representative Petri dish cultures of $S$. nodorum and $P$ glomerata colonies grown in the presence of thymol alone (10 ppm), Quadris alone (10 ppm), or
Quadris + thymol, each at $\mathbf{1 0} \mathbf{p p m}$. Fungi were cultured for 16 days. Control colonies were cultured in media with neither thymol nor fungicide. 


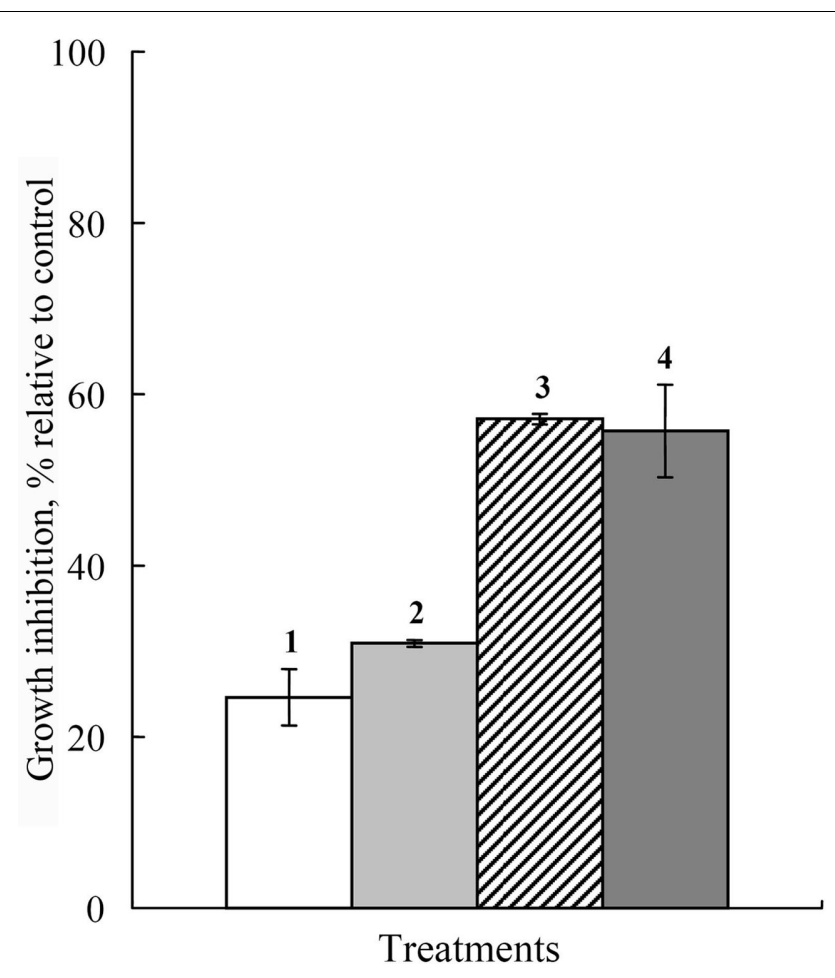

FIGURE 2 | Histograms showing percent growth inhibition of $S$. nodorum on PDA-media supplemented with thymol alone, the fungicide Dividend alone, or with Dividend + thymol as compared to controls (0\% inhibition). (1) Thymol, $10 \mathrm{ppm}$ alone; (2) Dividend, $1 \mathrm{ppm}$ alone; (3) Dividend, 1 ppm + thymol, 10 ppm; (4) Dividend, 10 ppm. Bars represent SE.

effect of $44 \%$ growth inhibition based on the growth inhibition caused by each of these compounds alone, at these concentrations. A similar trend of enhancement was found with thymol and Folicur. Folicur alone at a concentration of $0.5 \mathrm{ppm}$ caused low suppression (29\%) of A. alternata development. But Folicur at the same concentration combined with thymol at $10 \mathrm{ppm}$, a concentration at which growth inhibition of A. alternata is negligible, inhibited pathogen growth by approximately $50 \%$. To achieve this level of growth inhibition by Folicur alone, its concentration would have to be doubled ( 1 ppm; Figure 4).

The ability of another putative chemosensitizer, 4-HBA, to enhance fungitoxicity of Folicur was examined against $A$. alternata and a toxigenic fungus $F$. culmorum. Co-application of $0.5 \mathrm{ppm}$ of Folicur with 4-HBA at 200 ppm resulted in significant improvement of the fungicidal activity toward F. culmorum (Figure 5) and A. alternata (Table 2). Folicur alone at $0.5 \mathrm{ppm}$ inhibited the growth of either fungus at approximately 30\%. But, Folicur combined with 4-HBA, at a non- or negligible fungicidal level, resulted in almost doubling antifungal activity against both pathogens (Table 2).

Chemosensitization potential of 2,3-DHBA was tested for enhancing the growth-inhibitory effect of Folicur toward $A$. alternata grown on Czapek agar. Folicur and this benzaldehyde achieved relatively low rates of growth inhibition when applied alone, $10 \%$ at $0.5 \mathrm{ppm}$ and $2.5 \%$ at $1.0 \mathrm{ppm}$, respectively. However,

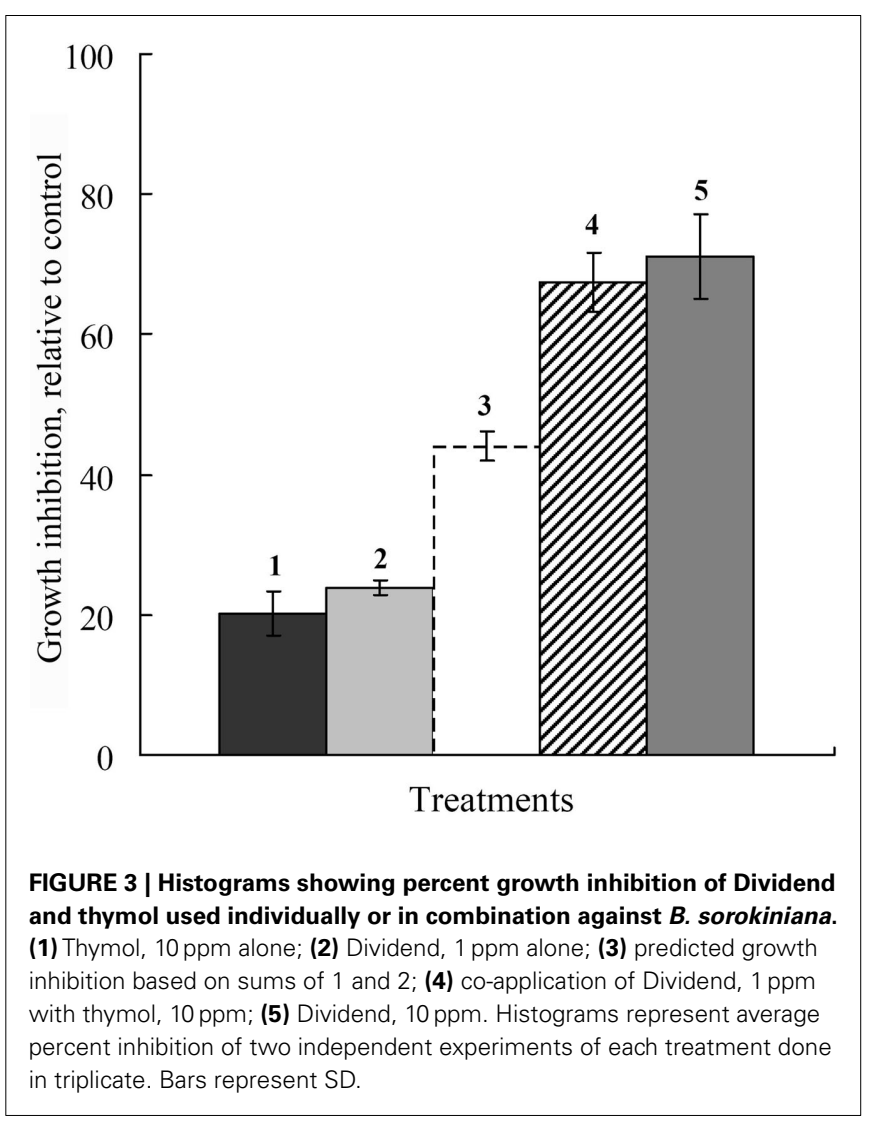

at these same concentrations, when co-applied, there was significant increase of growth inhibition (approximately 25\%) of this pathogen, implying there is some type of synergistic interaction that more than doubles antifungal activity (Figure 6).

The chemosensitizing impact of FCL, containing extracellular metabolites from liquid cultures of the biocontrol isolate FS-94, on S. nodorum after 7 days of growth appeared to be additive to treatment by Folicur or Dividend. When FCL was applied at low $(2 \%$ $\mathrm{v} / \mathrm{v})$ or moderate $(10 \% \mathrm{v} / \mathrm{v})$ concentrations with Folicur, growth inhibition of $S$. nodorum after 7 days was almost equal to that of the arithmetic sum of these substances used alone (Figure 7). However, after 9 days of growth the results showed that the effect of FCL on the antifungal activity of Folicur was significantly above additive. The co-application of these substances promoted maintenance of a higher level of fungicidal activity as the fungus continued to grow. The growth-inhibitory effect of Folicur alone, decreased by the 9 th day to $49 \%$, while the inhibitory effect of Folicur combined with FCL remained at $69 \%$ to the end of observation period (23 days).

The sensitivity of $S$. nodorum to Dividend was also enhanced under the influence of FCL. In cultures of the fungus with Dividend and FCL, at a concentration $2 \% \mathrm{v} / \mathrm{v}$, pathogen growth rate slowed significantly from the rate of growth if cultured with Dividend alone $(p<0.05)$ starting on the 17 th day after inoculation (Figure 8). This difference increased step-by-step as the fungus underwent vegetative growth (on 20th day $p=0.003$; on 23rd day, $p=0.00001)$. At the earlier stages of colony growth 
(corresponding to the 14th and 17th days, Figures 8 and 9) no differences were observed in the inhibitory effects between the individual application of the fungicide alone and the combined application of fungicide with FCL. As time progressed, the fungus began to overcome the fungicidal effect of the Dividend alone dose (Figure 8, line 3), and the difference between colony area of the control and Dividend-treated fungi began to decrease (Figure 9). During the same period, however, colony growth on

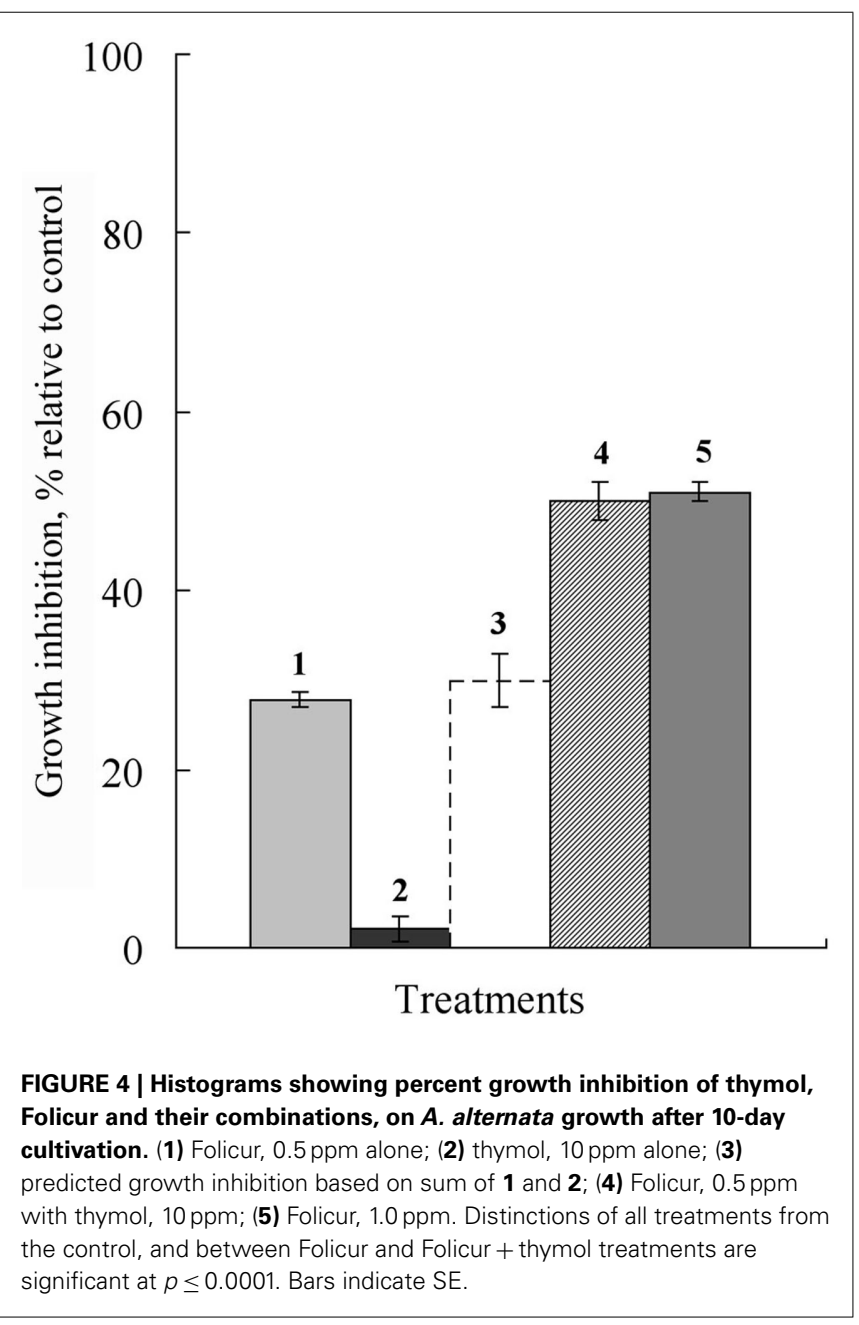

Dividend + FCL combinations reduced much more significantly as compared to the controls. Thus, as time went on, differences in colony area between control and co-application treatments increased. On day 20 and 23, these differences were two or threefold greater, respectively, than between controls and where the fungicide was applied alone (Figure 9). Thus, co-application of the fungicide with FCL resulted in a certain prolongation of the antifungal effect against S. nodorum and decreased growth rate of the fungus. Moreover, starting on the 20th day of cultivation, a noteworthy enhancement of antifungal activity was observed if Dividend was co-applied with a weakly inhibitory concentration of FCL (Table 3 ).

When FCL was added to the culture medium to a final concentration of $10 \% \mathrm{v} / \mathrm{v}$ and Dividend was at a concentration of $0.01 \mathrm{ppm}$, growth inhibition of $S$. nodorum reached $20-30 \%$ to that of controls. In order to achieve this same level of growth inhibition using Dividend alone a fivefold increase $(0.05 \mathrm{ppm})$ of this fungicide would be required (Figure 10).

\section{DISCUSSION}

Crop protection using industrial fungicides is a powerful tool for effective control of many plant pathogenic fungi. However, extensive use of such fungicides is now recognized, worldwide, to be associated with a range of environmental risks (De Costa and Bezerra, 2011). Restrictive regulations have been applied to the use of fungicides in order to minimize these risks. Nevertheless, multiple applications of several different fungicides may be required at times in order to achieve an effective control of fungal pathogens (e.g., Eckert and Ogawa, 1988). Such multifaceted applications of fungicides can, in turn, exacerbate xenobiotic perturbations to the environment. Another disturbing consequence of the commercial use of fungicides for plant protection is development of resistance by plant pathogenic fungi that damage important agricultural crops. Such resistance renders any protective effects relatively short-lived and eventually uneconomical (Steffens et al., 1996; Brent and Hollomon, 2007). Several different strategies are being developed to counter, or reduce, the development of resistance in fungi and lower the environmental impact of the use of fungicides. These include plant breeding for disease resistance (Russell, 1978; Polak and Bartos, 2002; Niks et al., 2011), the search for novel low-persistent and highly effective active ingredients, biopesticides of plant or microbial origin (Bailey et al., 2010;

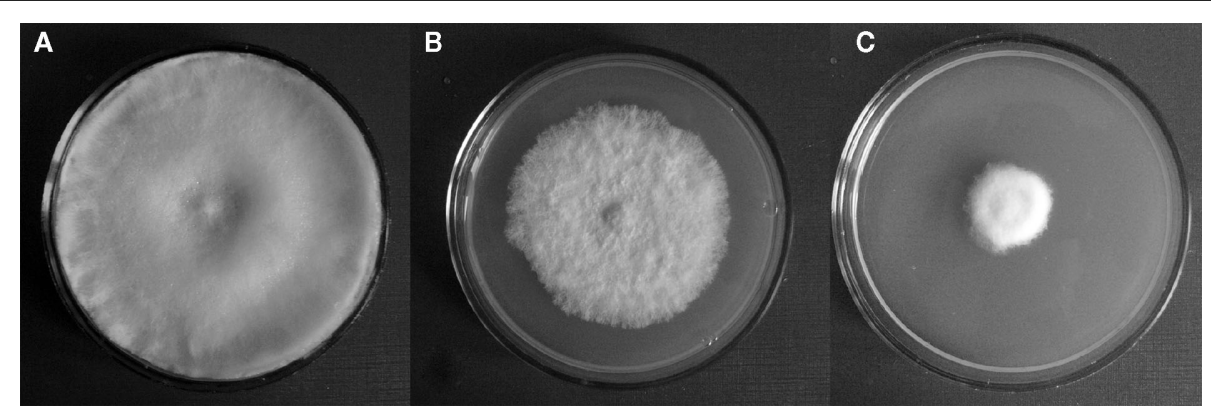

FIGURE 5 | Ten-day growth of colonies of $F$ culmorum cultured in the presence of: (A) 4-Hydroxybenzaldehyde (4-HBA), 200 ppm; (B) Folicur, 0.5 ppm; and (C) Folicur, $0.5 \mathrm{ppm}$, with 4-HBA, $200 \mathrm{ppm}$. 
Table 2 | Fungicidal effect of 4-HBA, Folicur and their mixture toward F. culmorum and A. alternata at day 10 of in vitro testing.

\begin{tabular}{|c|c|c|c|c|c|c|c|}
\hline \multirow[t]{3}{*}{ Fungi } & \multirow{3}{*}{$\begin{array}{l}\text { Diameter of control } \\
\text { colonies, } \mathrm{mm}\end{array}$} & \multicolumn{6}{|c|}{ Substances and concentrations, ppm } \\
\hline & & \multicolumn{2}{|c|}{ 4-HBA, 200} & \multicolumn{2}{|c|}{ Folicur, 0.5} & \multicolumn{2}{|c|}{ 4-HBA, 200 + Folicur, 0.5} \\
\hline & & $\begin{array}{l}\text { Colony } \\
\text { diameter, mm }\end{array}$ & $\begin{array}{l}\text { Growth } \\
\text { inhibition, \% }\end{array}$ & $\begin{array}{l}\text { Colony } \\
\text { diameter, } \mathrm{mm}\end{array}$ & $\begin{array}{l}\text { Growth } \\
\text { inhibition, \% }\end{array}$ & $\begin{array}{l}\text { Colony } \\
\text { diameter, mm }\end{array}$ & $\begin{array}{l}\text { Growth } \\
\text { inhibition, \% }\end{array}$ \\
\hline F. culmorum & $90.0 \pm 0.0$ & $89.0 \pm 0.3$ & $1.1 \pm 0.4$ & $60.8 \pm 1.1$ & $32.0 \pm 0.8$ & $35.8 \pm 0.9$ & $61.0 \pm 1.8$ \\
\hline A. alternata & $90.0 \pm 0.0$ & $84.0 \pm 0.7$ & $6.7 \pm 0.8$ & $67.0 \pm 0.0$ & $28.0 \pm 0.0$ & $32.7 \pm 0.0$ & $64.0 \pm 0.0$ \\
\hline
\end{tabular}

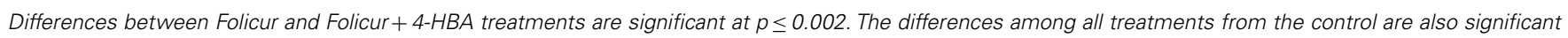
$(p<0.05)$

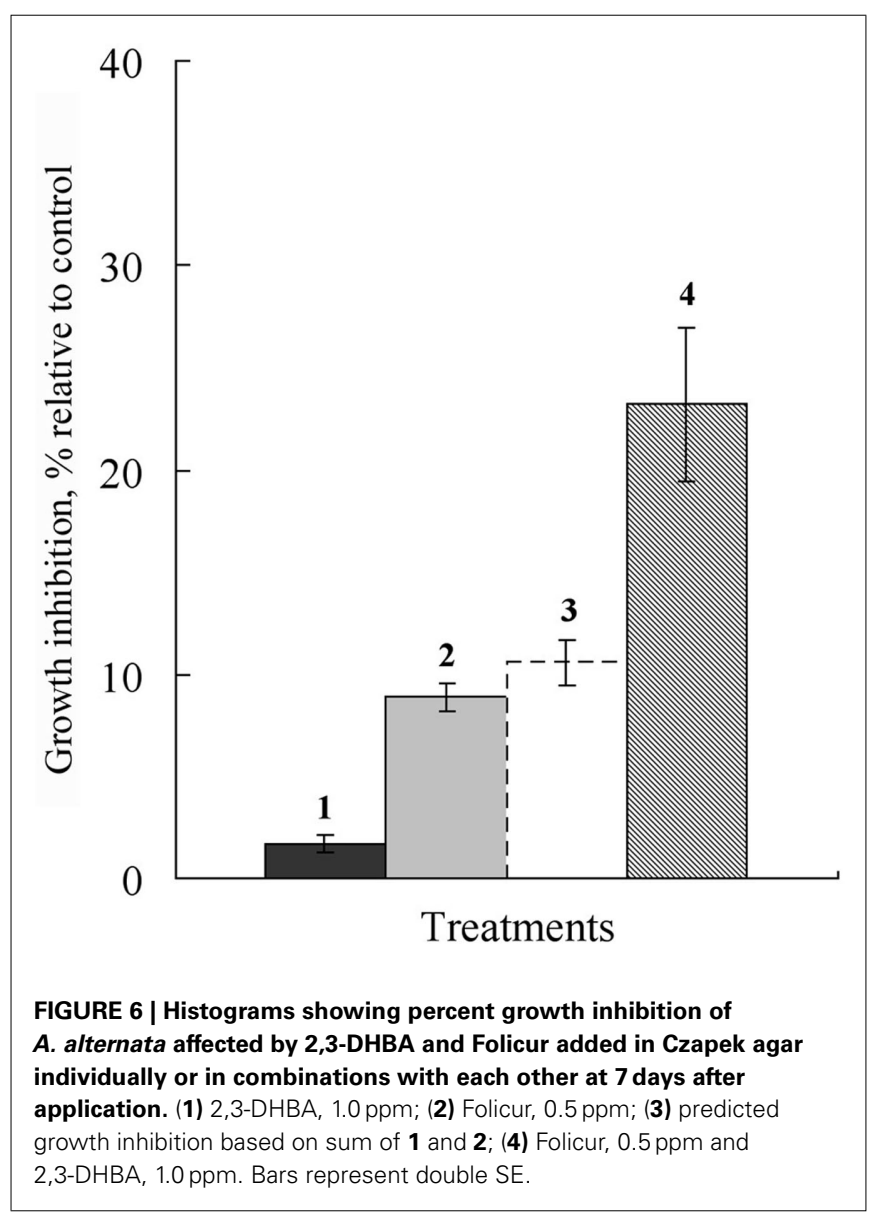

Dubey et al., 2011; Pretorius and van der Watt, 2011; Shcherbakova, 2011), and use of fungicides in combination with biocontrol agents (Elad, 2003; Buck, 2004; Gilardi et al., 2008; Baus et al., 2011).

Of particular interest in our study is a strategy that searches for compounds that specifically target the stress-response systems of pathogens, and thereby enhances their sensitivity to fungicides. Such a strategy is called chemosensitization. One concept underlying the selection of putative chemosensitizers consists of increasing fungitoxic activity by disrupting fungal oxidative stressresponse systems that protect the fungus from reactive oxygen species (ROS; Kim et al., 2006a, 2007, 2011). This approach has been demonstrated in vitro successfully by assays that include

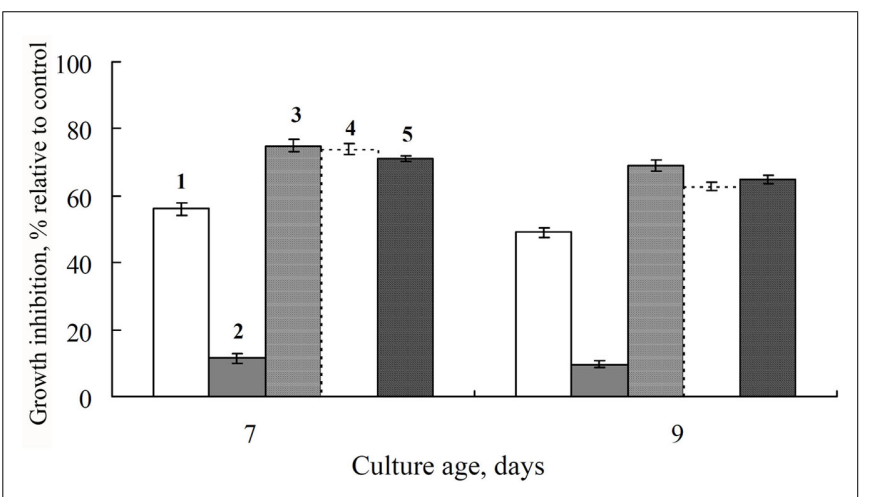

FIGURE 7 | Enhancement of Folicur growth-inhibitory effect against $S$. nodorum by co-application of the fungicide with filtrates of cultural liquid (FCL) produced by a biocontrol isolate, FS-94, of $F$ sambucinum after 7 or 9 days of cultivation. (1) Folicur, alone, 0.25 ppm; (2) FCL, 2 volume percent, alone; (3) Folicur, $0.25 \mathrm{ppm}+\mathrm{FCL}, 2$ volume percent; (4) Predicted percent of growth inhibition based on the sum of $\mathbf{1}$ and $\mathbf{2}$; (5) Folicur, $0.5 \mathrm{ppm}$. Bars represent SE. Percent growth inhibition distinctions between treatments $\mathbf{1}$ and $\mathbf{3}$ are significant at $p<0.002$ and 0.05 on 7th and 9 th days, respectively. Differences between mean growth inhibitions of $\mathbf{3}$ and $\mathbf{4}$ on 9 th day are significant at $p<0.03$.

fungicides/antibiotics with compounds that disrupt the oxygen stress-response system, enhancing sensitivity of mycotoxigenic fungi and human pathogenic fungi of medical importance to antifungal agents (Kim et al., 2006b, 2008; Faria et al., 2011; Kim and Campbell, 2011). Various natural phenolic compounds and their derivatives that possess anti- or oxidative activity have been shown to be effective chemosensitizing agents in above referred reports.

In our current study we used some of the agents previously reported to be effective against human pathogens to evaluate their chemosensitizing potential in vitro toward several plant pathogenic fungi. Such agricultural fungi are often controlled with triazole and/or strobilurin-type fungicides in practice. Our research was focused on studying the ability of 2,3-DHBA, thymol, and 4-HBA to improve fungicidal action, emphasizing the discovery of any significant enhancement. We tested selected concentrations of both fungicide and test agent which had a sub-fungicidal impact on the plant pathogens, when applied alone. Preliminary experiments suggested (data not shown) that B. sorokiniana, $S$. nodorum, $P$. glomerata, F. culmorum, and Alternaria fungi differed in sensitivity to the fungicides and putative sensitizers used in our 
study. Therefore, the sub-fungicidal concentrations of these substances applied for individual treatments and in co-applications differed for each pathogen. When fungicides and chemosensitizers, 2,3-DHBA, thymol, and 4-HBA, were co-applied at higher dosages

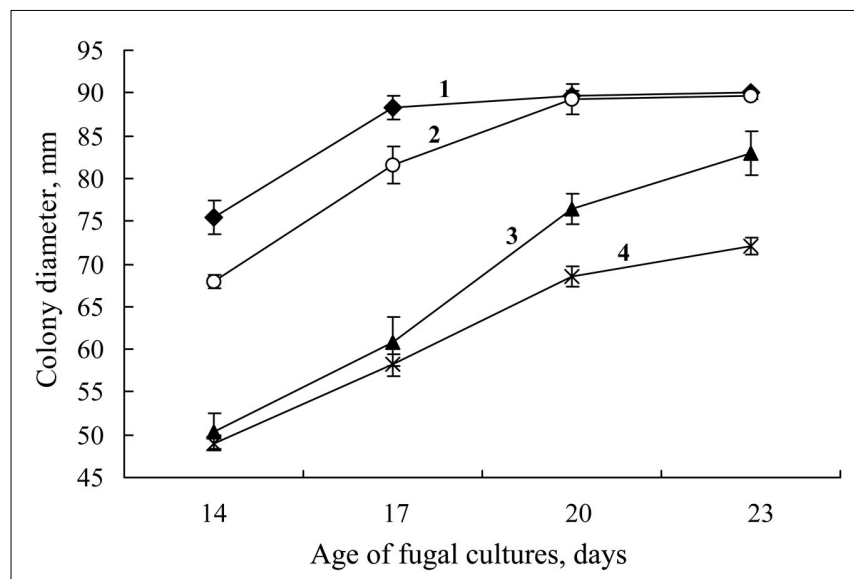

FIGURE 8 | Change in colony diameter of $S$. nodorum by number of days cultured on PDA or PDA supplemented with Dividend, alone, or Dividend combined with the filtrate of cultural liquid (FCL) of a biocontrol Fusarium sambucinum isolate FS-94. (1) Control colonies grown without the fungicide or FCL. (2) FCL, final concentration $2 \%$ by volume; (3) Dividend, $0.01 \mathrm{ppm}$ alone; (4) Dividend, $0.01 \mathrm{ppm}+\mathrm{FCL}, 2$ volume percent.

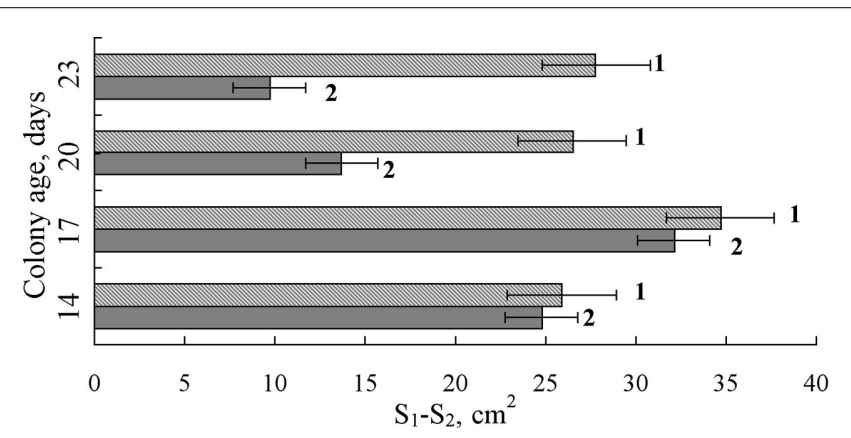

FIGURE 9 | Progressive increase in differences $\left(S_{1}-S_{2}\right)$ between colony areas $\left(\mathrm{cm}^{2}\right)$ of Stagonospora nodorum treated $\left(\mathrm{S}_{2}\right)$ with Dividend combined with FCL (1) or Dividend alone (2), compared with area of control colonies $\left(S_{1}\right)$, after 14, 17, 20, and 23 days of culture.

$\mathrm{FCL}$ - filtrate of cultural liquid produced by a biocontrol isolate of F. sambucinum, FS-94 at a final concentration of 2 volume percent. Dividend concentration is $0.01 \mathrm{ppm}$. Bars represent $2 \times \mathrm{SE}$. than at sub-fungicidal levels, an additive effect was observed (data not shown). In such cases, any enhancement of antifungal activity beyond an additive effect between the compounds was masked. Therefore, we tested the compounds at sub-fungicidal concentrations so that the predicted effect based on the arithmetical sum of growth inhibition of the tested substances did not exceed $50-60 \%$.

Our results with the use of two benzo analogs (4-HBA and 2,3 -DBA) as well as a natural phenolic product, thymol, at the selected sub-fungicidal concentrations showed these substances provided significant improvement of antifungal activity of triazole and strobilurin-type fungicides toward all tested pathogenic fungi. Our data coincide with previous findings (Faria et al., 2011; Kim and Campbell, 2011) showing that the tested phenolic substances are promising as chemosensitizers of plant pathogens to industrial fungicides. Also, our observation of the chemosensitizing impact for taxonomically unrelated plant pathogenic fungi suggests these chemosensitizers possibly attack the oxidative stressresponse systems common to various fungi (Roman et al., 2007) such as, Mn-SOD (mitochondrial superoxide dismutase) and MAPK pathway.

We found that FCL arrested radial growth of $S$. nodorum colonies, inducing 10-30\% inhibition depending on FCL concentration employed. Our experiments showed that FCL is a putative source of natural chemosensitizing compounds, enhancing and prolonging the fungicidal effects of Folicur and Dividend. The results with $S$. nodorum suggest that metabolites in the cultural liquid of F. sambucinum are of interest as a new source of natural sensitizers, at least toward the wheat leaf/glume blotch agent. Further research is necessary to examine the scope and the level of FCL sensitizing activity, as well as the isolation and identification of the component(s) responsible for this activity.

The F. sambucinum isolate FS-94 has been previously shown to be a biocontrol agent of some plant pathogenic Fusaria (Shcherbakova et al., 2006, 2008). It is also known to synthesize metabolites that induce systemic acquired resistance (SAR) in potato (Shcherbakova et al., 2006) and tomato, by activating and priming a salicylic acid (SA)-dependent plant signaling system (Shcherbakova et al., 2011). Along with its direct antifungal effects on S. nodorum, FCL of FS-94 has no phytotoxicity (Shcherbakova et al., 2009; Semina et al., 2011) and, as shown in our current research, can also sensitize this plant pathogen to commercial fungicides. It very well may be that different components of the FCL have different modes of action. Understanding such details will provide an additional advantage if they are to be used as chemosensitization tools in the future. Interestingly,

Table 3 | Enhancement of antifungal activity in vitro toward the growth of $S$. nodorum after co-application of Dividend and filtrate of cultural liquid (FCL) produced by a biocontrol isolate of $F$ sambucinum, FS-94.

Day after inoculation

Growth inhibition, \% relative to average diameter of control colonies

FCL, $2 \% \mathrm{v} / \mathrm{v} \quad$ Dividend, $0.01 \mathrm{ppm} \quad$ Dividend, $0.01+\mathrm{FCL}, 2 \% \mathrm{v} / \mathrm{v}$

\begin{tabular}{|c|c|c|c|c|}
\hline & & & & \\
\hline & & & Co-application & Arithmetical sum \\
\hline 20 & $0.6 \pm 0.03$ & $15 \pm 0.27$ & $24 \pm 0.52$ & $15.6 \pm 0.30$ \\
\hline 23 & $0.2 \pm 0.01$ & $8 \pm 0.20$ & $20 \pm 0.20$ & $8.2 \pm 0.21$ \\
\hline
\end{tabular}




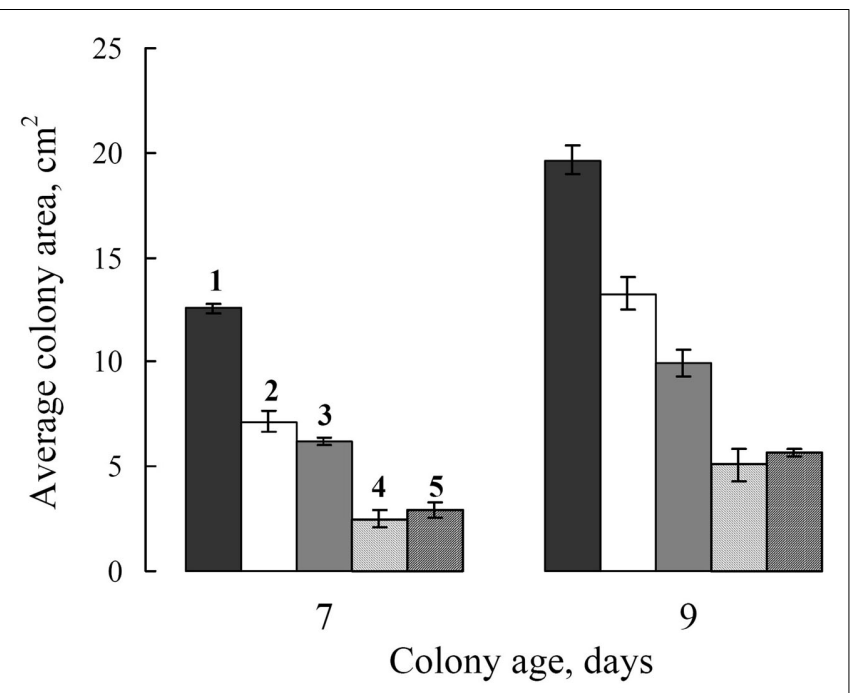

FIGURE 10 | Colony size of $S$. nodorum after 7 and 9 days of culture on: (1) PDA, alone (control); (2) PDA supplemented with FS-94 cultural liquid filtrate (FCL) to final concentration $10 \%$ by volume, alone; (3) PDA supplemented with Dividend, 0.01 ppm, alone; (4) PDA supplemented with Dividend, $0.01 \mathrm{ppm}+\mathrm{FCL}, 10$ volume percent, and; (5) PDA supplemented with Dividend, $\mathbf{0 . 0 5} \mathbf{p p m}$. Bars represent SE.

salicylaldehyde that mimics the action of SA, a key plant signaling molecule which is involved in SAR, targets the cellular antioxidation system in aflatoxigenic fungi, functioning in a chemosensitization manner (Kim et al., 2010a).

Prolongation of the fungicidal activity with FCL is a new and previously uninvestigated property. Such fungicidal prolongation is something that should be verified for other chemosensitizers. Discovery of this phenomenon, in our opinion, is of special importance for agricultural fungicides. In contrast to antifungal drugs applied in medicine, plant protection remedies are not designed for the total extermination of a pathogen (this

\section{REFERENCES}

Bailey, A., Chandler, D., and Grant, W. P. (2010). Biopesticides: Pest Management and Regulation. Cambridge: CABI Publishing.

Baus, O., Reineke, A., and BerkelmannLohnertz, B. (2011). Control of grey mould by application of gibberellin acid inhibitor (Regalis ${ }^{\circledR}$ ) and management practices in Vitis vinifera (cv. Riesling). IOBC/WPRS Bull. 67, 49-53.

Brent, K. Y., and Hollomon, D. W. (2007). Fungicide Resistance in Crop Pathogens: How can it be Managed? Brussels: Fungicide Resistance Action Committee.

Buck, J. W. (2004). Combinations of fungicides with phylloplane yeasts for improved Control of Botrytis cinerea on geranium seedlings. Phytopathology 94, 196-202.
De Costa, P., and Bezerra, P. (2011). Fungicides: Chemistry, Environmental Impact and Health Effects. Hauppauge, NY: NOVA Publishes.

Dubey, N. K., Shukla, R., Kumar, A., Singh, P., and Prakash, B. (2011). "Global scenario on application of natural products in integrated pet management programmes," in Natural Products in Plant Pest Management, ed. N. K. Dubey (Preston: CABI), 1-20.

Eckert, J. W., and Ogawa, J. M. (1988). The chemical control of Postharvest diseases: deciduous fruits, berries, vegetables and root/tuber crops. Annu. Rev. Phytopathol. 26, 433-469.

Elad, Y. (2003). Biological control of Botrytis cinerea. IOBC/WPRS Bull. 26, 7-8.

Faria, N. C. G, Kim, J. H., Gonçalves, L. A. P., Martins, M., de, L., Chan, K. L., and Campbell, B. C.

is unachievable under natural conditions). They are designed to delay the development of disease for as long as possible. Co-application of sensitizing agents with agricultural fungicides could retard emergence of plant diseases using decreased dosage rates, while reducing the number of treatments, making fungicide applications more economically sound.

Another potential advantage of using chemosensitizers in agriculture is the opening of new avenues for solving the problem of emerging fungicide-resistant mutants. Until now, the most common way to control resistance to fungicides was by increasing dosages until they are effective. This approach, unfortunately, adds to the pesticide pressure on the environment. In our experiments with thymol and Dividend we found that their co-application produced, in vitro, as strong of a fungal growth inhibition as would require at least a 10 -fold higher concentration of Dividend individually against $S$. nodorum and B. sorokiniana. This finding shows the promising possibility of developing effective, ecologically compatible, and biodegradable chemosensitizers that could be used in combinations with fungicides. In addition, the relatively low cost and availability of chemosensitizers and the diminished overall cost of chemical treatments (chemosensitizer + fungicide), would be very attractive from the agricultural economic viewpoint.

The first priority in continuing our investigation on chemosensitization of plant pathogenic fungi to fungicides should be to examine the tested compounds on enhancing fungicidal activity in planta, on host plants. Another necessary step is to produce mutants of our tested pathogens that are resistant to Dividend, Folicur or Quadris. The effort would then include an attempt to overcome their elevated resistance using co-applications of effective sensitizers revealed in this research.

\section{ACKNOWLEDGMENTS}

This research was under project \#3745 of the International Science and Technology Center (ISTC), a collaborative program between Russian and American scientists, funded by the U. S. Department of Agriculture, Agricultural Research Service.

(2011). Enhanced activity of antifungal drugs using natural phenolics against yeast strains of Candida and Cryptococcus. Lett. Appl. Microbiol. 52, 506-513.

Gilardi, G., Gullino, M. L., and Garibaldi, A. (2008). Effect of fungicides and of biocontrol agents against powdery mildew of turnip. Commun. Agric. Appl. Biol. Sci. 73 21-29.

Kim, J. H., and Campbell, B. C. (2011). "Chemosensitization of fungal pathogens to antimicrobial agents using phenolic compounds," in Prospects and Applications for Plant-Associated Microbes, A Laboratory Manual, Part B: Fungi., 212-214, eds A. M. Pirttilä, and S. Sorvari (Paimio: BioBien Innovations), 328.

Kim, J. H., Campbell, B. C., Mahoney, N., Chan, K. L., and May, G. S. (2006a). Targeting antioxidative signal transduction and stress response system: control of pathogenic Aspergillus with phenolics that inhibit mitochondrial function. J. Appl. Microbiol. 101, 181-189.

Kim, J. H., Mahoney, N., Chan, K. L., Molyneux, R. J., and Campbell, B. C. (2006b). Controlling food contaminating fungi by targeting their antioxidative stress system with natural phenolic compounds. Appl. Microbiol. Cell Physiol. 70, 735-739.

Kim, J. H., Campbell, B. C., Mahoney, N., Chan, K. L., and Molyneux, R. J. (2010a). Chemosensitization of aflatoxigenic fungi to antimycin A and strobilurin using salicylaldehyde, a volatile natural compound targeting cellular antioxidation system. Mycopathologia 171, 291-298.

Kim, J. H., Campbell, B. C., Mahoney, N., Chan, K. L., Molyneux, R. J., and Xiao, C.-L. (2010b). Use 
of chemosensitization to overcome fludioxonil-resistance in Penicillium expansum. Lett. Appl. Microbiol. 51, 177-183.

Kim, J. H., Campbell, B. C., Mahoney, N., Chan, K. L., Molyneux, R. J., and May, G. S. (2007). Enhanced activity of strobilurin and fludioxonil by using berberine and phenolic compounds to target fungal antioxidative stress response. Lett. Appl. Microbiol. 45, 134-141.

Kim, J. H., Mahoney, N., Chan, K. L., and Campbell, B. C. (2011). Antifungal activity of redox-active benzaldehydes that target cellular antioxidation. Ann. Clin. Microbiol. Antimicrob. 10, 23.

Kim, J. H., Mahoney, N., Chan, K. L., Molyneux, R. J., May, G. S., and Campbell, B. C. (2008). Chemosensitization of fungal pathogens to antimicrobial agents using benzo analogs. FEMS Microbiol. Lett. 281, 64-72.

Niks, R. E., Parlevliet, J. E., Lindhout, P., and Bai, Y. (2011). Breeding Crops with Resistance to Diseases and Pests. Wageningen: Wageningen Academic Publishers.

Pinto, E., Pina-Vaz, C., Salgueiro, L., Goncalves, M. J., Costa-deOliveira, S., Cavaleiro, C., Palmeira, A., Rodrigues, A., and Martinezde-Oliveira, J. (2006). Antifungal activity of the essential oil of Thymus pulegioides on Candida, Aspergillus and dermatophyte species. J. Med. Microbiol. 55, 1367-1373.

Polak, J., and Bartos, P. (2002). Natural sources of plant disease resistance and their importance in the breeding. Czech J. Genet. Plant Breed 38, 146-149.

Pretorius, J. C., and van der Watt, E. (2011). "Natural products from plants: commercial prospects in terms of antimicrobial, herbicidal and bio-stimulatory activities in an integrated pest management system," in Natural Products in Plant Pest Management, ed. N. K. Dubey (Preston: CABI), 42-90.

Roman, E., Arana, D. M., Nombela, C., Alonso-Monge, R., and Pla, J. (2007). MAP kinase pathways as regulators of fungal virulence. Trends Microbiol. 15, 181-190.

Russell, G. E. (1978). Plant Breeding for Pest and Disease Resistance. London: CABI Publishing.

Semina, Y. U. V., Shcherbakova, L. A., and Devyatkina, G. A. (2011). Anti-Stagonospora nodorum activity in filtrates of Fusarium sambucinum cultural liquids after growing the fungus on different nutrient media. Mycologia Fitopathologia 45, 563-570.

Shcherbakova, L. A. (2011). "Some natural proteinaceous and polyketide compounds in plant protection from diseases and their potential in green consumerisation," in Natural Products in Plant Pest Management, ed. N. K. Dubey (Preston: CABI), 109-133.

Shcherbakova, L. A., Devyatkina, G. A., Dorofeeva, L. L., and Nazarova, T. A. (2006). "Inducing the resistance to Fusaria causing wheat root rot and tomato wilt with a nonpathogenic Fusarium sambucinum isolate," in Proceedings of All-Russian science-and-practical conference "Immunity induction as an important line of investigation in plant protection" Vol. 1, ed. B. Vyazyomy (Moscow: VIZR-VNIIF), 74-77.

Shcherbakova, L. A., Dorofeeva, L. L. Devyatkina, G. A., Sokolova, G. D., and Fravel, D. R. (2008). Control of wheat root rots under field conditions with compounds produced by Fusarium sambucinum strain FS94. J. Plant Pathol. 90(Suppl. 2), 338-339.

Shcherbakova, L. A., Nazarova, T. A. Mikityuk, O. D., and Fravel, D. R. (2011). Fusarium sambucinum isolate FS-94 induces resistance against Fusarium wilt of tomato via activation and priming of a salicylic aciddependent signaling system. Russ. J. Plant Physiol. 58, 808-818.

Shcherbakova, L. A., Semina, Y. U. V., Shumilina, D. V., Fravel, D. R., and Dorofeeva, L. L. (2009). "Elicitors from a biocontrol Fusarium sambucinum and Pseudomonas fluorescens protect wheat from multiple fungal pathogens," in 5th Meeting of the IOBC Working Group of "Induced Resistance in Plants against Insects and Diseases," Granada, 42-43.

Steffens, J. J., Pell, E. J., and Tien, M. (1996). Mechanisms of fungicide resistance in phytopathogenic fungi. Curr. Opin. Biotechnol. 7, 348-355.

Conflict of Interest Statement: The authors declare that the research was conducted in the absence of any commercial or financial relationships that could be construed as a potential conflict of interest.

Received: 19 December 2011; accepted: 21 February 2012; published online: 09 March 2012.

Citation: Dzhavakhiya V, Shcherbakova L, Semina $Y$, Zhemchuzhina $N$ and Campbell B (2012) Chemosensitization of plant pathogenic fungi to agricultural fungicides. Front. Microbio. 3:87. doi: 10.3389/fmicb.2012.00087

This article was submitted to Frontiers in Fungi and Their Interactions, a specialty of Frontiers in Microbiology.

Copyright (C) 2012 Dzhavakhiya, Shcherbakova, Semina, Zhemchuzhina and Campbell. This is an open-access article distributed under the terms of the Creative Commons Attribution Non Commercial License, which permits non-commercial use, distribution, and reproduction in other forums, provided the original authors and source are credited. 